\title{
Cyanine dyes derived inhibition of insulin fibrillization
}

\section{Vus, Kateryna}

2019-02-15

Vus , K, Girych , M , Trusova , V , Gorbenko , G , Kurutos , A, Vasilev , A, Gadjev , N \& Deligeorgiev , T 2019 , ' Cyanine dyes derived inhibition of insulin fibrillization ' , Journal of Molecular Liquids, vol. 276 , pp. 541-552 . https://doi.org/10.1016/j.molliq.2018.11.149

http://hdl.handle.net/10138/322833

https://doi.org/10.1016/j.molliq.2018.11.149

cc_by

acceptedVersion

Downloaded from Helda, University of Helsinki institutional repository.

This is an electronic reprint of the original article.

This reprint may differ from the original in pagination and typographic detail.

Please cite the original version. 


\section{Accepted Manuscript}

Cyanine dyes derived inhibition of insulin fibrillization

Kateryna Vus, Mykhailo Girych, Valeriya Trusova, Galyna Gorbenko, Atanas Kurutos, Aleksey Vasilev, Nikolai Gadjev, Todor Deligeorgiev

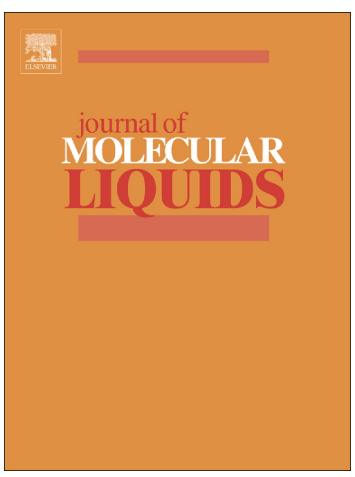

PII:

S0167-7322(18)33768-1

DOI: https://doi.org/10.1016/j.molliq.2018.11.149

Reference:

MOLLIQ 10059

To appear in:

Journal of Molecular Liquids

Received date:

21 July 2018

Revised date:

8 November 2018

Accepted date:

28 November 2018

Please cite this article as: Kateryna Vus, Mykhailo Girych, Valeriya Trusova, Galyna Gorbenko, Atanas Kurutos, Aleksey Vasilev, Nikolai Gadjev, Todor Deligeorgiev , Cyanine dyes derived inhibition of insulin fibrillization. Molliq (2018), https://doi.org/ 10.1016/j.molliq.2018.11.149

This is a PDF file of an unedited manuscript that has been accepted for publication. As a service to our customers we are providing this early version of the manuscript. The manuscript will undergo copyediting, typesetting, and review of the resulting proof before it is published in its final form. Please note that during the production process errors may be discovered which could affect the content, and all legal disclaimers that apply to the journal pertain. 


\section{Cyanine dyes derived inhibition of insulin fibrillization}

Kateryna Vus ${ }^{1}$, Mykhailo Girych ${ }^{2}$, Valeriya Trusova ${ }^{1}$, Galyna Gorbenko $^{1}$, Atanas Kurutos ${ }^{3}$, Aleksey Vasilev ${ }^{4}$, Nikolai Gadjev ${ }^{4}$, Todor Deligeorgiev ${ }^{4}$

${ }^{1}$ Department of Nuclear and Medical Physics, V.N. Karazin Kharkiv National University, 4 Svobody Sq., Kharkiv 61022, Ukraine;

${ }^{2}$ Department of Physics, University of Helsinki, 2a Gustaf Hällströmin katu, Helsinki, FIN-00014, Finland;

${ }^{3}$ Institute of Organic Chemistry with Centre of Phytochemistry, Bulgarian Academy of Sciences, Acad. G. Bonchev str., bl. 9, 1113 Sofia, Bulgaria;

${ }^{4}$ Department of Pharmaceutical and Applied Organic Chemistry, Faculty of Chemistry, Sofia University St. Kliment Ohridski, 1 blv. J. Bourchier, Sofia, 1164, Bulgaria

\section{Abstract}

The potential of novel cyanine dyes to inhibit the insulin amyloid formation was evaluated using thioflavin $\mathrm{T}$ fluorescence assay, quantum-chemical calculations, molecular docking and molecular dynamics simulations. According to the ability to suppress the insulin fibrillization under physiological conditions the examined compounds were found to follow the order: trimethines $>$ pentamethines $>$ monomethines $>$ heptamethines. Of these, the trimethines 3-3 and 3-5, and pentamethines 5-3 and 5-9 almost completely prevented the protein aggregation by retarding both nucleation (except 3-3) and elongation processes. The quantum-chemical calculations revealed a complex relationship between the dye structure and its inhibitory effects. The molecular docking studies showed that most cyanines bind specifically to the L17 ladder of the B chain, located at the dry steric zipper of the insulin fibril protofilament, and form the stable complexes with the helices of the insulin monomer. The molecular dynamics simulations provided evidence for the increase of insulin helicity in the presence of cyanines. Collectively, the presented findings highlight two possible mechanisms by which cyanines can inhibit the insulin fibrillization: i) stabilization of the native protein structure followed by the retardation of the protein nucleation (all dyes); and ii) blocking the lateral extension of $\beta$-sheets via the dye-protein stacking interactions $(3-3,3-5,5-3,5-9)$. Overall, the obtained results may prove of importance for the design of small molecules capable of preventing amyloid fibril formation by insulin and other proteins. 
Key words: cyanine dyes; insulin; small-molecule amyloid inhibitors; native structure stabilization; thioflavin $\mathrm{T}$

\section{Corresponding author:}

Dr. Kateryna Vus

Aeroflotskaya St. 12, Kharkiv 61031, Ukraine

Tel: (+380 57) 3438244

E-mail: kateryna_vus@yahoo.com 


\section{Introduction}

The formation and accumulation of particular type of protein aggregates, amyloid fibrils, in human tissues and organs is associated with dozens of severe disorders including Alzheimer's disease (AD), Parkinson's disease, type II diabetes, familial amyloid polyneuropathy, etc. [1,2]. The process of amyloid self-assembly typically consists of two consecutive phases: nucleation, in which partially unfolded protein monomers form an oligomeric nucleus and the subsequent growth phase [3]. Recent evidence points to soluble oligomers as the primary toxic species of amyloids presumably due to their ability to create channels in the cell membrane, followed by disruption of calcium homeostasis and free radical formation [4,5]. In view of this, significant efforts have been made towards development of the therapeutic agents that block early stages of amyloid formation [6,7], reduce the lifetime of toxic oligomers by acceleration of fibrillization and prevent fibril fragmentation [8]. The following classes of anti-amyloid drugs have been designed for the above purposes: i) proteins, peptides and covalently modified peptides [9,10]; ii) modified DNA [11]; iii) fullerenes [12]; and iv) small organic molecules [13]. The latter include: surfactants, copper/zinc ion chelators [13], flavonoids (e.g., oleuropein aglycone, epigallocatechin gallat, curcumin, etc.) [14-16], and organic dyes such as Congo red (CR) [17], azo dyes [18], etc. Among the above compounds, peptide inhibitors seem to be the most promising agents for prevention of fibrillization process in vivo due to their high biocompatibility and affinity for the amyloidogenic core sequence of the fibril-forming proteins [9,19]. However, small molecules have some advantages over peptide amyloid inhibitors, associated with their ability to easily cross the blood brain barrier and avoid immunological response, higher stability in biological fluids and tissues, lower flexibility enabling efficient binding, etc. [20-22]. In vitro studies reported a wide number of small-molecule inhibitors of fibrillogenesis, differing in structure and mode of inhibitory effect. Specifically, it has been demonstrated that: i) an orcein-related polyphenol, O4, promoted conversion of $A \beta 1-42$ oligomers into mature amyloid fibrils [9]; ii) curcumin inhibited oligomer formation of $A \beta$, lysozyme and human islet amyloidogenic polypeptide [23]; iii) epigallocatechingallate prevented $\alpha$-synuclein and transthyretin aggregation by stabilizing native conformation of the protein and favoring the formation of amorphous aggregates [23]; iv) indole derivatives inhibited lysozyme fibrillization through affecting both nucleation and elongation stages of fibrillogenesis [24], etc. However, most of the above compounds have not been tested yet in clinical trials, and some of them, viz. curcumin [23] and di-iodo form of clioquinol [25], did not show effect in the prevention and treatment of AD. Furthermore, even though the existing antiamyloid drugs predominantly interfere with $A \beta$ self-assembly, the exact modes of action of these compounds remain elusive. In view of the lack of clinically approved drugs against amyloid 
diseases, the design of small molecules that inhibit amyloid fibril formation is of paramount importance in biomedical research.

Cyanine dyes represent a remarkable class of organic compounds, which have found numerous applications in theranostic of tumors [26,27] and fluorescence imaging of biomolecules $[28,29]$ due to their: i) high extinction coefficients; ii) high affinity for biomolecules; iii) longwave absorption and emission bands (near-infrared compounds), enabling highly sensitive in vivo measurements due to the absence of the autofluorescence of the biological molecules in this region, etc. [30,31]. Furthermore, some studies showed the potential of cyanines to be employed as antiamyloid drugs, e.g., symmetrical cationic thiacarbocyanine N744 inhibited tau aggregation [32]. However, handling of cyanine-based anti-amyloid agents has been challenging due to their cytotoxicity and ability to self-aggregation [33], suggesting the necessity of designing novel inhibitors and investigating their modes of action both in vitro and in vivo. Polymethine bridge length, heterocyclic substituents, length of the aliphatic substituents on the nitrogen atom of benzazole chromophore, etc., were reported to modulate the inhibition potency of the cyanine inhibitors of tau aggregation [33], and therefore, the dyes, possessing these structural differences were selected for our study.

This study was aimed at assessing the ability of novel cyanine dyes to prevent amyloid fibril formation by bovine insulin in vitro using thioflavin $\mathrm{T}$ assay, quantum-chemical calculations, molecular docking and molecular dynamics simulations. Insulin is a small helical protein hormone, playing a crucial role in glucose metabolism. Bovine insulin has been successfully employed to treat diabetes due to its high structural similarity to the human variant. Insulin amyloid deposits are a preclinical sign of injection-localized amyloidosis in diabetic patients, and these species were observed in Parkinson's disease, as well [34,35]. Furthermore, amyloid fibrillation is a limiting factor in production, long-term storage and delivery of insulin pharmaceutical formulations [36]. In this context, the search for effective small molecular inhibitors of the pathogenic insulin aggregation may prove of importance for prevention of impaired absorption from the affected site in patients, as well as for a more cost-effective storage of insulin [36,37]. Our goals were: i) to estimate the kinetic parameters of insulin fibril formation in the presence of novel cyanine dyes; ii) to compare the influence of the polymethine bridge length and heterocyclic substituents on the dye ability to suppress the insulin self-assembly; iii) to establish a correlation between the quantum-chemical characteristics of the polymethine compounds and their inhibition potency; iv) to determine potential binding sites for the novel dyes in the native and fibrillar insulin; v) to uncover the mechanism of action of the most effective cyanine inhibitors of insulin fibrillogenesis.

\section{Materials and methods}




\subsection{Materials}

The grades of reagents used for this study were as follows. Bovine insulin ( $\geq 25$ USP

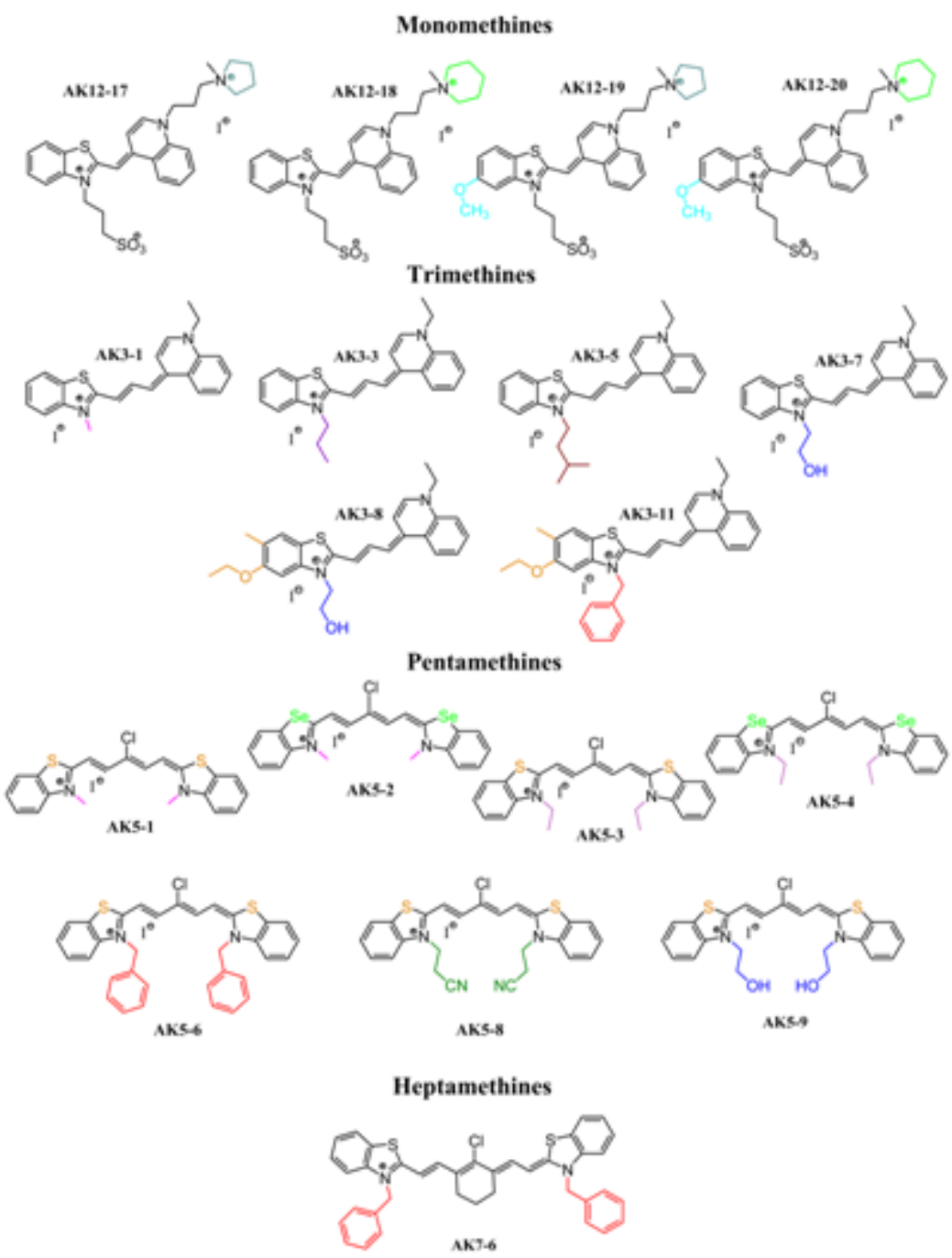

\section{Scheme 1.}

Chemical structures of the cyanine dyes under study.

units/mg (HPLC)), ethylenediaminetetraacetic acid (EDTA) (purity of $\geq 95 \%$ ), $\mathrm{NaCl}(\geq 99 \%, \mathrm{AR}$ grade), dimethyl sulfoxide (99\%, ACS reagent), methanol (99.8\%, ACS reagent), N-(2hydroxyethyl)piperazine-N0-2-ethanesulfonic acid (Hepes) ( $\geq 99.5 \%$ (titration)), and thioflavin $\mathrm{T}$ (ThT) $(\geq 65 \%)$ were from Sigma. Monomethine [31], trimethine [38], pentamethine [30] and heptamethine [39] cyanine dyes (analytical grade) (Scheme 1) were synthesized and purified by recrystallization from methanol in the University of Sofia, Bulgaria, as described previously. Phosphotungstic acid hydrate (high-purity grade) for electron microscopy was from REACHIM. The water used for this study was purified by ion exchange or distillation. All other reagents were 
used without further purification. Cyanine dye stock solutions $(100 \mu \mathrm{M})$ were prepared in dimethyl sulfoxide or methanol, while ThT powder was diluted in HEPES buffer (20 mM HEPES, $0.1 \mathrm{mM}$ EDTA, $150 \mathrm{mM} \mathrm{NaCl}, \mathrm{pH} 7.4)$ to the concentration of $150 \mu \mathrm{M}$. The dye concentrations were determined spectrophotometrically using Cary 100 UV-Vis spectrophotometer (Varian Instruments, Walnut Creek, CA). The extinction coefficients $(\varepsilon)$ at absorption maxima $\left(\lambda_{a b s}\right)$ for pentamethine (AK5-1, AK5-2, AK5-3, AK5-4, AK5-6, AK5-8, AK5-9), heptamethine (AK7-6) cyanine dyes in dimethyl sulfoxide, and monomethine (AK12-17, AK12-18, AK12-19, AK12-20), trimethine cyanine dyes (AK3-1, AK3-3, AK3-5, AK3-7, AK3-8, AK3-11) in methanol are presented in Table 1, while the extinction coefficient of ThT was taken as $\varepsilon_{412}=23800 \mathrm{M}^{-1} \mathrm{~cm}^{-1}$.

\subsection{The kinetics of amyloid formation monitored by thioflavin $T$ assay}

The insulin stock solution $(10 \mathrm{mg} / \mathrm{ml})$ was prepared in $10 \mathrm{mM}$ glycine buffer $(\mathrm{pH} 1.6,150$ $\mathrm{mM} \mathrm{NaCl}$ ). The kinetics of insulin fibrillization was monitored by ThT assay. Specifically, 96well plates (black plastic with clear glass bottom, Greiner Bio-One, Frickenhausen, Germany) filled with ThT $(10 \mu \mathrm{M})$, protein $(20 \mu \mathrm{M})$ and cyanine dye $(0-$ control sample or $10 \mu \mathrm{M})$ were loaded into the fluorescence microplate reader (SPECTRAFluor Plus, Tecan, Austria), heated to $37^{\circ} \mathrm{C}$ and incubated under constant linear shaking (50 rpm) for up to several hours [40]. The TEM images of insulin fibrils formed in the absence of cyanine dyes are given in Figure S1, revealing the formation of the rod-like aggregates $c a . \sim 200-500 \mathrm{~nm}$ in length and $c a . \sim 20 \mathrm{~nm}$ in thickness similar to those observed by Iannuzzi et al. [41]. The ThT fluorescence was recorded over time at $485 \mathrm{~nm}$ (10 $\mathrm{nm}$ bandpass filter) with excitation at $430 \mathrm{~nm}$ ( $35 \mathrm{~nm}$ bandpass filter). Three replicates, corresponding to three wells for each sample, were used to minimize the well-to-well variation. The obtained kinetic curves (Figures 2-3) represent the mean of three replicates (standard error is about $5 \%$ ).

The quantitative characteristics of the fibrillization process were determined through approximating the time $(t)$ dependence of ThT fluorescence intensity at $485 \mathrm{~nm}(F)$ with the sigmoidal curve, using Origin Lab 7.5 software (Origin Lab Corporation, Northampton, MA, USA) [42]:

$$
F=F_{0}+\frac{F_{\max }-F_{0}}{1+\exp \left[k\left(t_{m}-t\right)\right]}
$$

where $F_{0}$ and $F_{\max }$ are ThT fluorescence intensities in the free form and in the presence of protein after the saturation has been reached, respectively; $k$ is the apparent rate constant for the fibril growth; $t_{m}$ is the time needed to reach $50 \%$ of maximal fluorescence. The lag time was calculated as: $t_{m}-2 / k$. 
To enhance fibril formation in the control sample, we performed a separate series of experiments, in which TRIS buffer (10 mM TRIS-HCl, $150 \mathrm{mM} \mathrm{NaCl}, \mathrm{pH}$ 7.4) solutions, containing ThT $(10 \mu \mathrm{M})$, insulin $(20 \mu \mathrm{M})$ and cyanine dye $(0$ or $10 \mu \mathrm{M})$, were incubated in thermostat at $37^{\circ} \mathrm{C}$ under constant orbital shaking with the increased speed $(115 \mathrm{rpm})$ for 115 hours. Indeed, the revealed ThT fluorescence response was about an order of magnitude greater as compared to that observed in the first series of experiments (Figure S2). Structures of the protein aggregates grown in the presence of the most effective insulin amyloid inhibitors, viz. AK3-3, AK3-5, AK5-3 and AK5-9, were compared with that of the control sample, using transmission electron microscopy (Figure S3).

\subsection{Transmission electron microscopy (TEM)}

For electron microscopy assay, a $5 \mu \mathrm{l}$ drop of the protein solution $(20 \mu \mathrm{M}$, taken from the tested sample after the fibril growth has been finished) was applied to a carbon-coated grid and blotted after $3 \mathrm{~min}$. A $10 \mu \mathrm{l}$ drop of $1.5 \%$ (w/v) phosphotungstic acid solution was placed on the grid, blotted after $30 \mathrm{~s}$, and then washed 2 times by deionized water and air dried. The resulting grids were viewed by EM-125 electron microscope (Selmi, Ukraine) (Figure S3).

\subsection{Quantum-chemical calculations}

The 3-21G(d,p) basis set was employed for the ground state $S_{0}$ geometry optimization of cyanine dyes, which is the appropriate for the organic compounds [43]. The obtained geometries of the dyes were used as starting conformations for calculation of the ground state dipole moment $\left(\mu_{g}\right)$, the energy of the ground state $\left(E_{g}\right)$ and dihedral angles between the donor (quinoline moieties) and acceptor (benzazole moieties) of the dye $(\varphi)$ with the 6-31G(d,p) basis set, offering reasonable estimates of the ground state properties [44,45]. All the above calculations were done by WinGamess (version 30 September 2017 R2). The optimized dye conformations were further used for estimation of the following descriptors by the semiempirical PM6 method (MOPAC 2016 Version18.012L - free academic license [46]): i) the energy of the highest occupied (EHOMO ) and lowest unoccupied ( ELUMO ) molecular orbitals; ii) the solvent-accessible area ( $C A$ ); iii) the cosmo volume (molecular volume) ( $C V)$; iv) the molecular length $(L)$, height $(H)$ and width ( $W)$; v) the polarizability of the molecule at the electric field strength $0 \mathrm{eV}(P)$. The Molinspiration software (http://www.molinspiration.com/cgi-bin/properties) was used for the calculation of lipophilicity of the examined compounds ( $\log P$ ) (http://www.vcclab.org/lab/alogps/), topological polar surface area (TPSA), and molecular weight (Mol.wt.) [47]. The ALOGPS 
method (http://www.vcclab.org/lab/alogps/) was employed to estimate the aqueous solubility ( $\log S$ ) [48]. All the calculated parameters are presented in Table S1.

\subsection{Molecular docking studies}

The molecular docking studies were carried out to identify the possible binding sites for the cyanine inhibitors of insulin fibrillization (revealed by ThT assay), and to elucidate the nature of the interactions involved in the dye-protein complexation in the native protein monomer (taken from the bovine insulin hexameric form, PDB ID: 2ZP6) and amyloid fibrils (the twoprotofilament model, containing 8 strands in each protofilament, based on the crystal structure of the segment LVEALYL (human insulin B chain residues 11-17), and downloaded from http://people.mbi.ucla.edu/sawaya/jmol/fibrilmodels/) [35]. It should be noted that the human insulin fibrils were used because of the lack of the crystallographic model for the bovine insulin fibrils. Furthermore, despite being stored in pancreas in the form of hexamers, at neutral $\mathrm{pH}$ and micromolar concentrations insulin dissociates into dimers and tetramers, and at the first step of the aggregation it dissociates into physiologically active monomers (possessing more exposed hydrophobic areas that dimers), which were therefore used in the molecular docking procedure $[40,49,50]$. Finally, the structures of cyanine dye monomers, optimized in Avogadro, were employed for the docking studies, because the monomers were predominant in buffer solution at micromolar concentrations [31,38,51], and they also showed the highest affinity for amyloid fibrils [52] and DNA, compared to dimers and higher order aggregates [43]. The top 10 energetically favorable dye-protein structures were obtained using the PatchDock algorithm that is suitable for the protein-ligand and protein-protein complexes, and then refined by the FireDock, as described previously [52]. The docked complexes were viewed by the Visual Molecular Dynamics (VMD) software (version 1.9.3).

\subsection{Molecular dynamics simulation of the dye-protein complexes}

The 20 ns MD simulations were performed using GROMACS software (version 5.1) and the CHARMM36 force field, which is update of CHARMM27, reported to provide the best reproduction of the insulin experimental behavior [53]. The input files for MD calculations were prepared for the energetically most favourable dye-protein complexes using the web-based graphical interface CHARMM-GUI. The .mol2-files of AK12-17, AK3-1, AK3-3, AK5-3 and AK7-6 were created in OpenBabelGUI 2.4.1, using the structures drawn in MarvinSketch (.mrv format). The topologies of the ligands were generated using the dye .mol2-files and CHARMM General Force Field, and subsequently modified by replacing partial charges with those assigned by RESP ESP charge Derive Server (designed to derive non-polarizable charges for new 
molecules) [54]. The temperature was set at $400 \mathrm{~K}$ to accelerate protein unfolding, that enabled us to test the stability of the free insulin monomer (2ZP6) and the most energetically favourable dyeprotein complexes obtained in docking studies. The systems were solvated in a rectangular box with a minimum distance of $10 \mathrm{E}$ from the protein to the edge of the box. The counter ions were added to neutralize and equilibrate the system. The MD simulations of the dye-protein complexes were carried out in the NPT ensemble. The systems were fully hydrated and contained 1 protein molecule (51 residues) and about 4384-4931 water molecules (the total number of atoms varied from 14009 to 15645 ). The molecular dynamic trajectories were saved every 1000 steps (1 ps interval) for subsequent analysis. The minimization and equilibration of the system were performed during 5000 (10 ps) and 500000 (1 ns) steps, respectively. The constant temperature conditions were provided by the V-rescale thermostat and there were no restraints in the simulations. The commands gmx rms, gmx rmsf, gmx gyrate and gmx sasa, included in GROMACS, were used to calculate the root-mean-square deviation ( $R M S D)$, root mean square fluctuations ( $R M S F)$, radius of gyration $\left(R_{g}\right)$, and solvent accessible surface area $(S A S A)$ per residue. The analyses of the protein secondary structure and distances between the dye and protein centres of mass were performed in VMD (version 1.9.3), using the Tcl scripts.

\section{Results and discussion}

As seen in Figures $2 \mathbf{A}, \mathbf{B}, 3 \mathbf{A}$, insulin samples treated with cyanine dyes at low dye-protein ratio 0.5, showed 2-28 times lower ThT fluorescence intensity (coupled with much smaller turbidity) than a control sample (not containing the cyanine dye), that displayed the largest ThT fluorescence response and the highest turbidity [55,56]. Accordingly, the kinetic parameters of the protein fibrillization significantly differ from those of the control sample, reflecting the inhibition of the protein aggregation (Table 1).

The effects of cyanine dyes on the insulin fibrillization appeared to depend on the polymethine bridge length of the compounds, and most dyes showed the ability to interfere with the protein aggregation, decreasing as follows: trimethines > pentamethines $>$ monomethines $>$ heptamethines (Table 1, $F_{\max } / F_{0}$ ). It is worth noting at this point that the most effective cyanine inhibitors of tau aggregation also had bridge length of three carbons [35]. Furthermore, AK3-3, possessing the highest inhibitory potential induced the decrease in $k$ value of insulin fibrillization, the effect being similar to that of cationic carbocyanine dye N744, which reduced

\section{Table 1.}

Spectral parameters of cyanine dyes and kinetic parameters of insulin fibrillization in the presence of cyanines. 


\begin{tabular}{|c|c|c|c|c|c|c|c|c|}
\hline Dye & $\begin{array}{c}\varepsilon^{a} \\
\mathrm{M}^{-1} \mathrm{~cm}^{-}\end{array}$ & $\begin{array}{c}\lambda_{a b s}{ }^{b} \\
\mathrm{~nm}\end{array}$ & $\begin{array}{l}F_{0}{ }^{c} \\
\text { a.u. }\end{array}$ & $F_{\max }^{d}$, a.u. & $k^{e}, \mathrm{~h}^{-1}$ & $t_{m}{ }^{f}, \mathrm{~h}$ & $\begin{array}{l}\text { Lag time } \\
\quad \mathrm{g}, \mathrm{h}\end{array}$ & $\underset{\max }{F} / F_{0}$ \\
\hline Control & - & - & $986 \pm 55^{i}$ & $35183 \pm 500$ & $2.7 \pm 0.1$ & $2.15 \pm 0.02$ & $1.4 \pm$ & $35.7 \pm 1.4$ \\
\hline $\begin{array}{c}\text { AK12- } \\
17\end{array}$ & 83200 & 507 & $715 \pm 63$ & $8694 \pm 50$ & $3.3 \pm 0.1$ & $1.75 \pm 0.01$ & $1.1 \pm 0.0$ & $12.2 \pm 1.6$ \\
\hline $\begin{array}{c}\text { AK12- } \\
18\end{array}$ & 77200 & 507 & $836 \pm 28$ & $7532 \pm 21$ & $4.8 \pm 0.1$ & $1.64 \pm 0.01$ & $1.2 \pm 0.0$ & $9.0 \pm 0.7$ \\
\hline $\begin{array}{c}\text { AK12- } \\
19\end{array}$ & 70700 & 517 & $756 \pm 54$ & $6683 \pm 42$ & $3.5 \pm 0.1$ & $1.70 \pm 0.01$ & $1.1 \pm 0.0$ & $8.8 \pm 0.7$ \\
\hline $\begin{array}{c}\text { AK12- } \\
20\end{array}$ & 59300 & 517 & $700 \pm 48$ & $6030 \pm 76$ & $1.6 \pm 0.1$ & $2.11 \pm 0.04$ & $0.9 \pm 0.0$ & $8.6 \pm 0.7$ \\
\hline AK3-1 & 136000 & 628 & $949 \pm 8$ & $3235 \pm 15$ & $5.9 \pm 0.2$ & $1.89 \pm 0.01$ & $1.6 \pm 0.0$ & $3.4 \pm 0.0$ \\
\hline AK3-3 & 159400 & 630 & $927 \pm 5$ & $1232 \pm 6$ & $0.6 \pm 0.0$ & $4.77 \pm 0.07$ & $1.4 \pm 0.1$ & $1.3 \pm 0.0$ \\
\hline AK3-5 & 150000 & 631 & $911 \pm 1$ & $1410 \pm 9$ & $1.6 \pm 0.0$ & $7.97 \pm 0.03$ & $6.7 \pm 0.1$ & $1.5 \pm 0.0$ \\
\hline AK3-7 & 161200 & 632 & $942 \pm 4$ & $1477 \pm 10$ & $7.8 \pm 0.6$ & $2.77 \pm 0.01$ & $2.5 \pm 0.0$ & $1.6 \pm 0.0$ \\
\hline AK3-8 & 145800 & 652 & $954 \pm 5$ & $4793 \pm 17$ & $6.3 \pm 0.1$ & $3.89 \pm 0.00$ & $3.6 \pm 0.1$ & $5.0 \pm 0.0$ \\
\hline $\begin{array}{c}\text { AK3- } \\
11\end{array}$ & 153200 & 649 & $954 \pm 4$ & $3367 \pm 23$ & $7.9 \pm 0.2$ & $4.60 \pm 0.01$ & $4.3 \pm 0.0$ & $3.5 \pm 0.0$ \\
\hline AK5-1 & 191158 & 652 & $902 \pm 27$ & $4793 \pm 47$ & $5.1 \pm 0.3$ & $2.00 \pm 0.01$ & $1.6 \pm 0.0$ & $5.3 \pm 0.2$ \\
\hline AK5-2 & 200442 & 663 & $899 \pm 21$ & $7634 \pm 55$ & $8.7 \pm 0.3$ & $2.34 \pm 0.01$ & $2.1 \pm 0.0$ & $8.5 \pm 0.3$ \\
\hline AK5-3 & 222041 & 652 & $943 \pm 3$ & $2441 \pm 22$ & $1.3 \pm 0.0$ & $12.06 \pm 0.03$ & $10.5 \pm 0.1$ & $2.6 \pm 0.0$ \\
\hline AK5-4 & 212768 & 665 & $939 \pm 10$ & $3523 \pm 35$ & $3.1 \pm 0.1$ & $4.60 \pm 0.02$ & $4.0 \pm 0.1$ & $3.8 \pm 0.1$ \\
\hline AK5-6 & 181648 & 660 & $975 \pm 17$ & $9812 \pm 54$ & $5.2 \pm 0.1$ & $3.52 \pm 0.00$ & $3.1 \pm 0.1$ & $10.1 \pm 0.2$ \\
\hline AK5-8 & 225549 & 660 & $858 \pm 56$ & $7590 \pm 79$ & $5.1 \pm 0.2$ & $1.20 \pm 0.01$ & $0.8 \pm 0.0$ & $8.8 \pm 0.7$ \\
\hline AK5-9 & 205688 & 657 & $940 \pm 6$ & $2319 \pm 11$ & $2.4 \pm 0.1$ & $7.36 \pm 0.02$ & $6.5 \pm 0.1$ & $2.5 \pm 0.0$ \\
\hline AK7-6 & 208902 & 817 & $905 \pm 35$ & $16839 \pm 100$ & $8.6 \pm 0.3$ & $4.17 \pm 0.00$ & $3.9 \pm 0.0$ & $18.6 \pm 0.8$ \\
\hline \multicolumn{9}{|c|}{$\begin{array}{l}a \text { - the extinction coefficients at absorption maxima }(b) \text { for } c \\
c-\text { ThT fluorescence intensity (at } 485 \mathrm{~nm} \text { ) in the free form. }\end{array}$} \\
\hline \multicolumn{9}{|c|}{$\begin{array}{l}d \text { - ThT fluorescence intensity (at } 485 \mathrm{~nm} \text { ) in the presence of protein after the saturation has been reached. } \\
e \text { - the apparent rate constant for the fibril growth. } \\
f \text { - the time needed to reach } 50 \% \text { of maximal fluorescence. } \\
g \text { - the lag time of the fibril formation. } \\
h \text { - ThT fluorescence response to the presence of insulin aggregates. }\end{array}$} \\
\hline \multicolumn{9}{|c|}{$\begin{array}{l}h \text { - Error bars represent standard errors of the parameters obtained by approximating the time dependence of ThT } \\
\text { fluorescence intensity at } 485 \mathrm{~nm} \text { with the sigmoidal curve (1), using Origin Lab } 8.0 \text { software (Nonlinear curve fit and } \\
\text { the No weighting options). }\end{array}$} \\
\hline
\end{tabular}

the filament length of tau aggregates without altering the lag time [34]. The above finding suggests that it is insulin elongation (not nucleation) that is affected by the presence of AK3-3. For the monomethine dyes and pentamethine AK5-8, a slight drop in lag time was accompanied by a slight increase in the apparent rate constant for the fibril growth, although a 2-fold decrease of $k$ was observed for AK1-20. The coincubation of trimethine/pentamethine/heptamethine compounds with the insulin samples resulted in a rise of both lag time, up to 7.5 times 


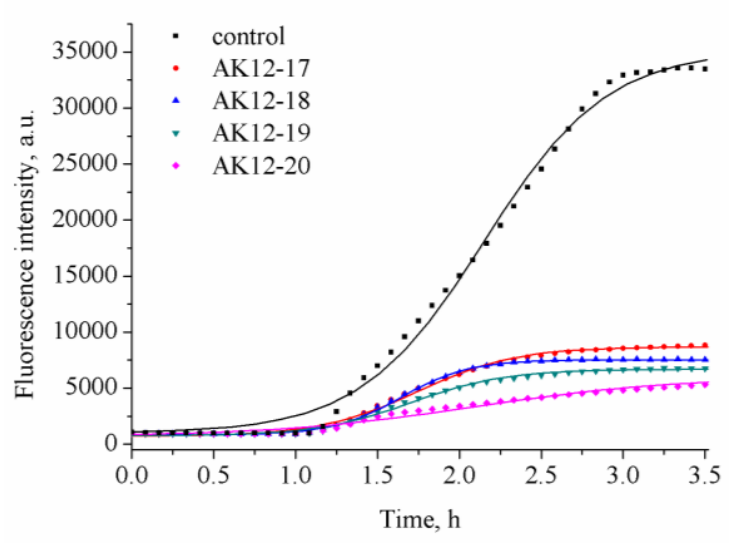

A

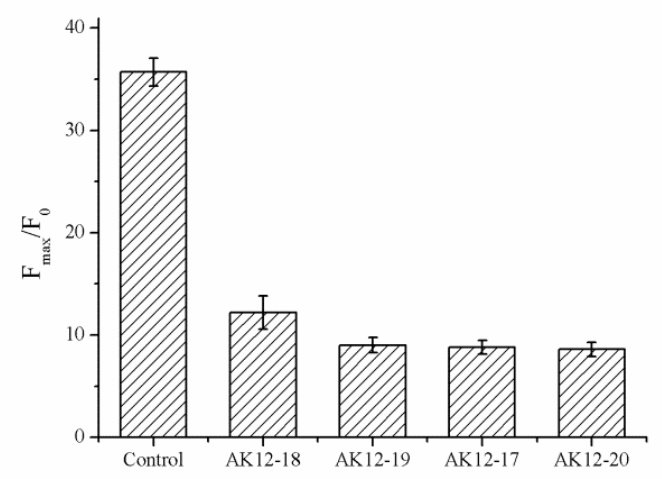

$\mathrm{C}$



B

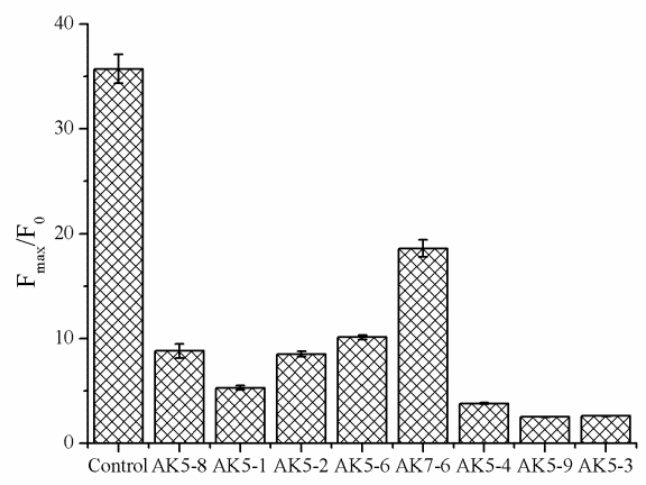

$\mathrm{D}$

\section{Figure 2.}

Kinetics of insulin fibrillization in the presence of monomethine (A) and pentamethine (B) cyanine dyes (experimental points and fitted curves). The inset (B) shows the kinetic curves for AK5-3 and AK5-9 in the range of 1000 - 3000 a.u. Each experimental point is the average of 3 identical samples. $F_{\max } / F_{0}$ value of insulin fibrillization in the presence of monomethine (C) and pentamethine, heptamethine (D) cyanine dyes. Protein, dye and ThT concentrations were 20, 10 and $10 \mu \mathrm{M}$, respectively.

(suppressed nucleation) and $k$, up to 3.2 times (enhanced elongation) compared to the control values, with the exception of AK3-5, AK5-3, AK5-9, which retarded the elongation and slowed down the nucleation of insulin fibrils. Notably, the experimental conditions affecting the nucleation and elongation do not always induce the changes of kinetic parameters in the same direction [56,57]. Taking into account the facts that the insulin secondary structure changes from almost completely helical to predominant $\beta$-sheets [58], and that the hydrophobic core of insulin (B-chain, the residues 11-17 [40]) is exposed to solvent during partial unfolding of the protein (enhanced by $\mathrm{NaCl}$ ), followed by the formation of oligomers and protofibrils [45,57], it can be 
supposed that the cyanine dyes are capable of stabilizing the native structure of insulin by, for example, preventing the destruction of $\alpha$-helixes. To verify this hypothesis, we performed a separate series of experiments (to increase the amount of mature insulin fibrils formed in control) and viewed the obtained protein aggregates at TEM (Figure S3). Surprisingly, superfibrillar twisted structures (ca. 536 $\pm 36 \mathrm{~nm}$ in width and up to several tens of micrometers in length) appeared in the absence of the cyanines (Figure S3, A) [59]. In turn, fuzzy amyloid-like fibrils (ca. $\sim 27 \pm 5 \mathrm{~nm}$ in width, and $c a . \sim 1.2 \pm 0.1 \mu \mathrm{m}$ in length) embedded in amorphous protein were observed in the presence of AK3-3 (Figure S3, B). Furthermore, spheroidal insulin assemblies possessing the diameters of $c a .30-650 \mathrm{~nm}$ were stabilized in the presence of AK3-5, AK5-3, AK5-9 (Figure S3, C-E). The latter effect was similar to that observed for insulin aggregation inhibited by eugenol, revealing that the cyanines can retain native protein species growing into mature fibrils by stabilizing large oligomers [60]. Indeed, AK3-5, AK5-3, AK5-9 appeared to be the most effective in preventing the insulin amyloid nucleation (i.e., extending the Lag time, Table 1), showing the off-pathway nature the observed spheroidal assemblies (Figure S3,C-E). In turn, AK3-3 inhibited only the elongation of the fibrils that resulted in the formation of the amyloid-containing amorphous species, being, presumably, less toxic than the large oligomers [61]. Interestingly, the observed insulin spherical aggregates may also represent a core of the giant insulin spherulites, containing few amounts of amyloid material, because they induced much lower ThT response as compared to that in the control sample (Figure S2) [62]. Furthermore, the native insulin secondary structure should be partially stabilized by the most effective cyanine inhibitors due to the fact that the smallest number of spheroidal aggregates, as well as the weakest ThT fluorescence response, were observed in the presence of AK3-5, as compared to that in the presence of AK5-3 and AK5-9 (Figure S3).
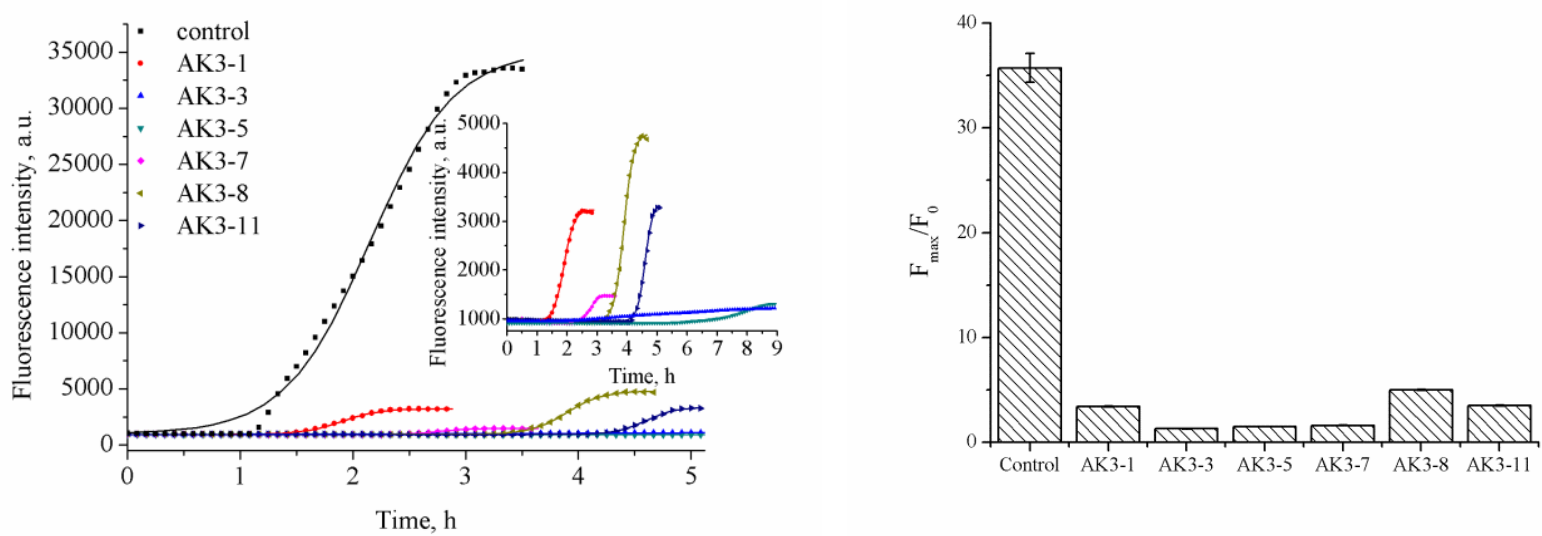
A

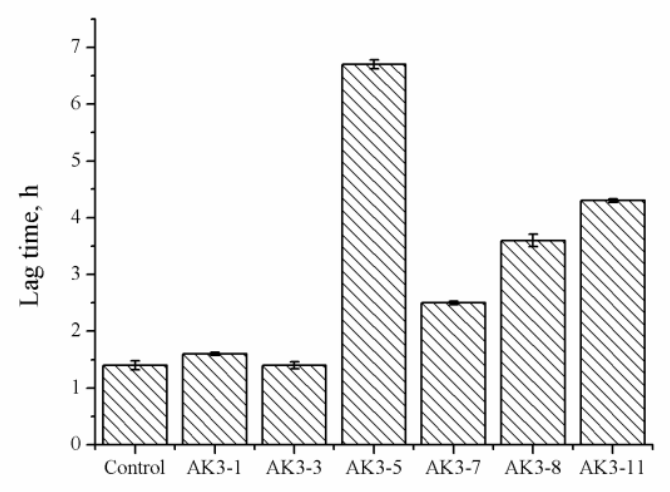

$\mathrm{C}$
B

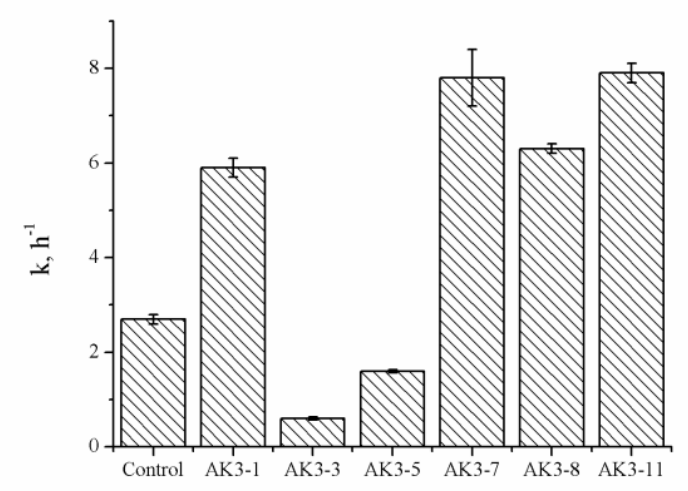

$\mathrm{D}$

\section{Figure 3.}

Kinetics of insulin fibrillization in the presence of trimethine cyanine dyes (experimental points and fitted curves). The inset shows the magnified curves in the range of $1000-5000$ a.u. Each experimental point is the average of 3 identical samples. (A). Kinetic parameters of insulin fibrillization (B-D). Protein, dye and ThT concentrations were 20, 10 and $10 \mu \mathrm{M}$, respectively.

The ThT fluorescence studies allowed us to uncover the effects of heterocyclic substituents on the dye ability to suppress the protein self-assembly, viz.: i) the increase in length of the aliphatic substituents on the nitrogen atom of benzazole chromophore from 1 to 2 and more carbons enhances the inhibition potency (decreased $\left.F_{\max } / F_{0}\right)$ of trimethines (AK3-3, AK3-5, AK3-7 compared to AK3-1) and pentamethines (AK5-3, AK5-4, AK5-9 compared to AK5-1, AK5-2). Interestingly, pentamethine dyes, possessing long alkyl chains in the quaternized nitrogen were reported to have far more higher affinity for bovine serum albumin than those with short substituents on the nitrogen atom of benzazole chromophore, suggesting that the novel dyes could inhibit amyloid fibril formation by interaction with native proteins [56]; ii) the presence of benzyl substituent in the $N$-alkyl substituents of benzazole moiety reduces the ability of AK3-11, AK5-6, AK7-6 to inhibit the insulin amyloid formation; iii) the replacement of $\mathrm{S}$ by Se in the benzazole heterocycle had negative impact on the inhibitory potential of AK5-2 and AK5-4 compared to AK5-1 and AK5-3, respectively; iv) the presence of $C \equiv N$ group in the $N$-alkyl of AK5-8 and the alkyl substituents in the 5-th and 6-th positions of benzazole moiety of AK3-8 decreases the dye inhibition potency; v) the long alkyl substituents of the quinoline ring, containing $\mathrm{N}$ methylpyrrolidine and $\mathrm{N}$-methylpiperidine groups significantly reduce the ability of the monomethines to interfere with the insulin aggregation; vi) the $\mathrm{OH}$-groups of the aliphatic substituents on the nitrogen atom of the benzazole chromophore (AK3-7 and AK5-9) induce 2-4 
times higher decrease in $F_{\max } / F_{0}$, than other trimethines (except AK3-3, AK3-5) and pentamethines (except AK5-3). The latter observation is in agreement with the results of Lee, Kisilevsky and Mishra, who reported that molecules containing hydroxyl, sulfonate or carbonyl groups inhibit amyloid fibril formation due to their strong interactions with amino acids $[22,63,64]$. Notably, monomethine dyes possessing sulfonate groups did not show high inhibitory potential presumably due to the bulky substituents in the quinoline moieties, which may reduce the dye affinity for the native insulin.

Our results showed that the monomethine compounds and heptamethine AK7-6 induced the least significant drop in ThT fluorescence intensity, despite the kinetic parameters provoking the increase of $F_{\max } / F_{0}$. These discrepancies may reflect the morphological changes in amyloid fibril structure (but not the decreased extent of the protein aggregation) induced by the dyes and resulting in the weaker ThT signal [65]. Furthermore, the monomethines represent the only class tested whose absorption spectra overlap with the emission band of ThT, suggesting that the Förster resonance energy transfer could also be responsible for the drop in ThT fluorescence (Table 1). In turn, AK7-6 was reported to form H-aggregates in aqueous solutions that may result in its lowest ability to interfere with the insulin amyloid formation [57]. In all cases, however, much lower turbidity of insulin solutions incubated with cyanine dyes, compared to the control sample, can be regarded as additional evidence for inhibition of amyloid fibril formation by this class of small molecules [66].

Notably, the examined cyanine dyes can also compete with ThT for the fibril binding sites, reducing the number of ThT molecules, associated with the protein assemblies [67]. Indeed, trimethine dyes 7519 and SH-516 were successfully employed for insulin and $\alpha$-synuclein amyloid detection, respectively $[68,69]$. Similarly, monomethine dye T-284 showed high sensitivity to amyloid $\alpha$-synuclein, despite the great impact of the substituents in the benzazole and quinoline moieties on the fluorescence response of the above dyes [70]. On the other hand, ThT has stronger affinity for insulin fibrils, as compared to other compounds (e.g., Congo Red, Nile Red) [65,70,71], and ThT assay is thought to be the most sensitive approach for monitoring the formation of insulin fibrils under acidic conditions [72], that reduces the probability of ThT competitive displacement from the fibril binding sites. Furthermore, while the inhibition occurs at the early stages of the insulin aggregation, the ability of the investigated dyes to displace ThT from the amyloid fibril binding sites could lead to the overestimation of their inhibitory potential, but not to a false positive effect. Finally, a separate series of TEM experiments showed that cyanine dyes possessing the highest inhibitory potential do inhibit insulin amyloid formation (Figure S3).

To gain deeper insights into the factors that may underlie the observed effects, the above experiments were complemented by the quantum-chemical calculations, molecular docking and 
molecular dynamics simulations, with particular emphasis on the mechanisms contributing to the inhibition of the insulin amyloid formation by the cyanine dyes.

The quantum-chemical calculations enabled us to establish a correlation between the experimentally determined $F_{\max } / F_{0}$ values and the quantum-chemical descriptors (Table S1). Remarkably, most of the examined dyes possess a planar (dihedral angle $\varphi$ between the benzazole and quinoline moieties varies from 163 to 180 degrees) hydrophobic core that is the common feature shared between the reported amyloid inhibitors [73,74]. In turn, the nonplanar monomethines showed the lowest inhibition potency (Table 1). Next, TPSA, LogP, and Mol.wt. values for AK3-3, AK3-5, AK5-3 were similar to those obtained for the cyanine inhibitors of tau aggregation, e.g., compound 11, capable of penetrating the blood-brain barrier, and thus, being the most attractive for biological experimentations, viz. pharmacokinetics studies $[33,75,76]$. The high polarizability $(P)$ of the planar cyanine dyes was supposed to account for the strong van der Waals interactions with a cross- $\beta$-sheet structure, followed by the stabilization of soluble tau oligomeric species $[33,77]$. Furthermore, $\alpha$-helices provide the surfaces suitable for the binding of $\pi$ delocalized ligands, as well [77]. Next, the quantitative structure-activity analysis of the polyphenolic inhibitors of $A \beta$ aggregation showed negative correlation between the fibrillization extent and the molecular descriptors such as $P$, Mol.wt., $C V$ and $C A$, indicating that the highest size factor leads to the greatest inhibitory effect [78]. In turn, the $P$ values derived for the dyes under investigation were lower than those reported previously, and a negative correlation between $P, L, M o l . w t$. and the inhibitor potency $F_{0} / F_{\max }$ was observed (the correlation coefficients were estimated to be $R Y=-0.6,-0.75$ and -0.73 , respectively), suggesting that either different mechanisms are involved in the prevention of insulin aggregation [77], or that the high ability of the dyes to self-associate in buffer solution and/or in the presence of native proteins prevents them from exerting specific inhibitory effects [79]. Indeed, the increase in cyanine dye aggregation with a polymethine bridge length (that is proportional to $L$ for all the compounds except heptamethines) was reported previously [80], while the binding of pentamethines and heptamethines to monomeric proteins turned out to shift the equilibria between various dye species towards the aggregate formation [30,56], in contrast to the trimethines [43], producing the largest decrease in $F_{\max } / F_{0}$ (Table 1). Overall, these data indicate that despite the lowest self-aggregation propensity the trimethines AK3-3, AK3-5 may have the strongest stacking interactions with the grooves on the amyloid protofibril surface, and thus, the highest ability to prevent lateral growth of the insulin fibrils [81], manifesting itself in the decrease of $k$ values compared to control (Table 1). Notably, the advantage of the tested dyes over polyphenoles, e.g., curcumin and quercetin, is that their tendency to aggregate is unlikely to play a key role in the prevention of the amyloid fibril 
formation, and thus, cyanines are less prone to exert non-specific inhibitory effects, which complicate the target validation [35,82]. Next, a moderate negative correlation $(R Y=-0.65)$ between $F_{0} / F_{\max }$ and HOMO-LUMO gaps indicates that the inhibition potency of cyanines increases along with their chemical reactivity, as well [83]. Likewise, only a weak correlation was revealed between $F_{0} / F_{\max }$ and the other descriptors (Table S1). Notably, the ground-state dipole moments of the monomethine dyes seem to be overestimated in $3-21 G(d, p)$ basis set as judged from the typical values of this parameter reported for cyanine compounds [84,85], although leaving the monomethines out of consideration did not improve the correlation. Finally, the $H$ values allowed us to suggest that the monomethines, AK5-6 and AK7-6 are unlikely to interact with channels running parallel to the long fibril axis, because the distance between the every second residue in a $\beta$-sheet is 6.5-6.95 $\AA$ [86]. Interestingly, Se has an important biological role: it is typically present in the active centers of human redox enzymes in the form of the selenocysteine that is more potent nucleophile than cysteine [87], while organoselenium molecules are of growing interest due to their important antioxidant properties [88-90]. According to our quantum-chemical calculations, replacement of S (AK5-1, AK5-2) to Se (AK5-2, AK5-4) induced a slight increase in the dye molecular volume and solvent-accessible area, and $\sim 15-20 \%$ decrease in lipophilicity (Table S1). In turn, dye molecules retained their almost planar structures (Table $\mathbf{S 1}$, torsion angle $\varphi_{0}$ ). These results show that hydrophobic dye-protein interactions are of great importance for the pentamethine inhibitors, leading to the $\sim 2$-fold increase in the AK5-1, AK5-3 inhibition potency $F_{0} / F_{\max }$ as compared to that of AK5-2, AK5-4, respectively (Table 1). Furthermore, the self-aggregation potency of Se-containing dyes should be lower, as compared to that of S-containing compounds, because $\mathrm{Se}$ is more potent nucleophile under physiological conditions [87]. However, AK5-1, AK5-3 monomers seem to form more stable complexes with the hydrophobic cavities of insulin and the dry steric zipper of insulin prefibrillar aggregates, than AK5-2, AK5-4.

The molecular docking studies indicated that the cyanine compounds (except AK7-6) and ThT tend to form the most stable complexes with L17 ladder (4-6 strands) of the B chain, located on the dry steric zipper of the insulin fibril protofilament, with their long axes parallel to the fibril axis, although the angle between the AK12-17 plane and the fibril extension direction was about 20 degrees (Figure 4) [20]. Furthermore, the above binding site also includes the residues C19 and L6 of the first and second protofilaments (B chain), respectively. Indeed, according to the molecular dynamics simulations, the ladders formed from $\mathrm{Y}$ and L possess high-affinity for ThT [91]. This binding mode was prevalent for pentamethines (AK5-3), trimethines (AK3-1, AK3-3) and ThT, but not for heptamethines (AK7-6) and monomethines (AK12-17), which exerted far 
less pronounced inhibitory effect on the insulin fibrillization than the other dyes (Figure S3). Interestingly, despite the high thickness of some dyes (Table S1), all compounds are capable of associating with fibrillar insulin parallel to the long fibril axis, since the binding site resides at the C-termini of LVEALYL $\beta$-strands (not in the grooves formed by the side chains of amino acids) (Figure 4). In the most energetically favorable dye-protein complex AK7-6 was attached to the fibril along the $\beta$-strand direction, interacting with the residues L17, Q4 and L6 of the first and second protofilament (B chain), respectively (Figure 4). However, the nonspecific primary binding sites for AK7-6, AK12-17 (Figure S3) and other monomethines (data not shown) were observed, embracing the $\mathrm{C}$ - and $\mathrm{N}$-termini of $\beta$-strands (coil structure) located at the fibril polar face. Most trimethines and pentamethines also associated with coil structure of the insulin fibril (secondary binding modes, data not shown). The analysis of the fibril binding sites revealed that the possibility of competitive binding of trimethine, pentamethine cyanine dyes and ThT, in principle, cannot be excluded. However, the inhibition of amyloid growth by, for instance, resveratrol, naproxen and ibuprofen was attributed to their binding to the surface grooves on the edge of IAPP and A $\beta$ fibrils, followed by blocking the lateral extension of the fibril $[91,92]$. In our case, the structure of the dry steric zipper interface could be destabilized by the bound dyes, resulting in the prevention of insulin cross- $\beta$ spine formation (Figure 4) $[40,93,94]$. The docking results coincide with the experimental data, showing that the most effective inhibitors, viz. AK33, AK3-5, AK5-3 and AK5-9 suppressed the fibril elongation, i.e. modulated the aggregation of the preformed nuclei. In turn, as in the case of resveratrol, no arguments were obtained in favor of the dye binding to the edge of the ending $\beta$-strand, which may inhibit the longitudual fibril growth $[9,94]$. Furthermore, Figure S4 shows that the monomethine compounds, AK7-6 and ThT do not compete for the same protein binding sites, making it unlikely that ThT is displaced from the fibril side-chain channel, rather its fluorescence intensity is reduced due to the inhibition of insulin aggregation. Similarly, the Förster resonance energy transfer between ThT and monomethines is hardly possible due to the lack of specific binding of the dyes to amyloid fibrils.

As seen in Figure 4, the most energetically favorable dye-protein complexes are formed as a result of the cyanine binding to different sites of the native insulin: i) AK5-3 and AK7-6 are attached to the B-chain $\alpha$-helix (residues 10-17) and to the B-chain residues 1-4 ( $\beta$-sheet includes the residues B3,B4); ii) AK3-1, AK12-17 and ThT associate with the B-chain residues 17-22 (3-10-helix includes the residues B20-B22), as well as to the B-chain residues 1-4 (AK3-1), F1 (ThT), and the A-chain $\alpha$-helix (residues 13-17) (AK12-17); iii) AK3-3 is associated with the B-chain residues 10-13 and F1. Thus, the typical binding modes for cyanines are (Figure S3): i) the association with the B-chain residues 1-4, the B-chain $\alpha$-helix and/or 3-10-helix, that is preferable for all dyes and may hamper the nucleus formation by preventing the interactions between the B-chains of the 
two partially unfolded insulin monomers [40,95]; ii) the binding between the B-chain C-terminal fragment (coil) and the A-chain $\alpha$-helix (residues 2-8) that is observed for ThT and AK7-6; iii) the binding between the B-chain 3-10 helix (residues 20-22) and the A-chain $\alpha$-helix (residues 13-17) that is found for AK12-17 and AK3-1; iv) the association with the B-chain C-terminal fragment (coil); and v) the association with the A-chain $\alpha$-helix (residues 2-8) that is revealed for AK3-3. On the whole, the cyanines seem to have high affinity for $\alpha-, 3-10$-helices of the B- chain and the A-chain $\alpha$-helix (residues 13-17), although, e.g., AK12-17 and AK7-6 are characterized by multiple binding sites, contrary to the other probes (Figure S3) $[95,96]$. The latter may reflect the low binding affinity of monomethine and heptamethine dyes for the native insulin because of the lack of specific binding sites, which also could result in their significantly lower (presumably nonspecific) inhibitory effect on the insulin aggregation (Table 1) [79]. The rest of the monomethines also lacked the specific binding sites, while the pentamethines were bound to the B-chain $\alpha$ - and 3-10 helices, and the trimethines formed stable complexes with both B-chain and A-chain helices (data not shown).

The molecular docking results support the above assumption that the novel dyes are capable of stabilizing the native insulin structure by interacting with the B-chain $\alpha$-helix (comprising the residues 11-17 of the amyloid core [40]). Likewise, Congo Red and other organic molecules were reported to inhibit the insulin fibrillization [18,97]. In turn, slowing down the insulin transformation from $\alpha$-helical- to $\beta$-sheet-rich structure was also induced by 1,2-Bis[4-(3sulfonatopropoxyl)phenyl]-1,2-diphenylethene, possessing higher affinity for the partially

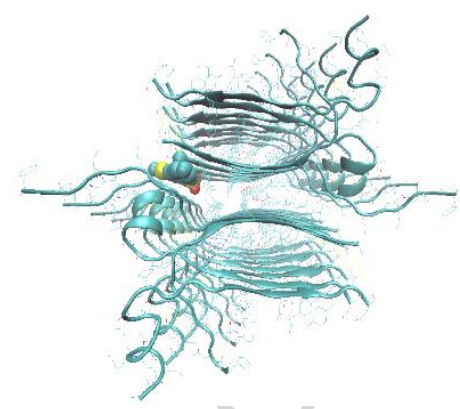

A



$\mathrm{D}$



B

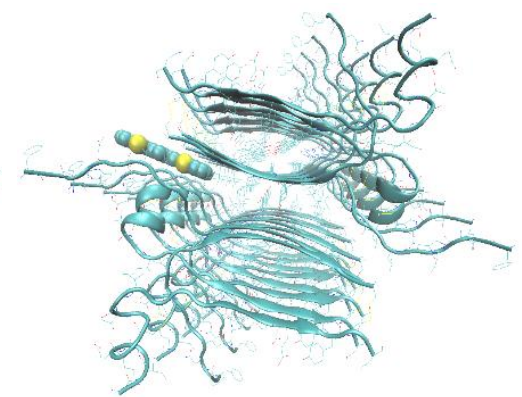

$\mathrm{E}$

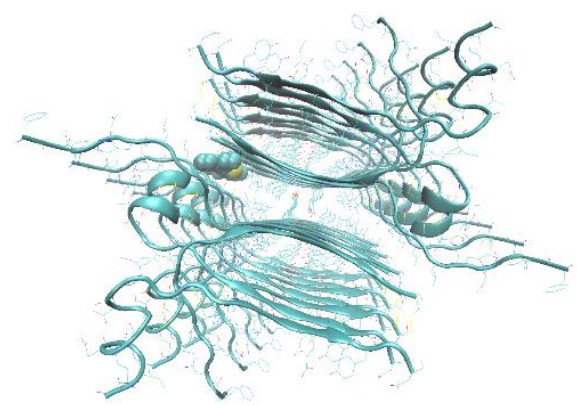

$\mathrm{C}$

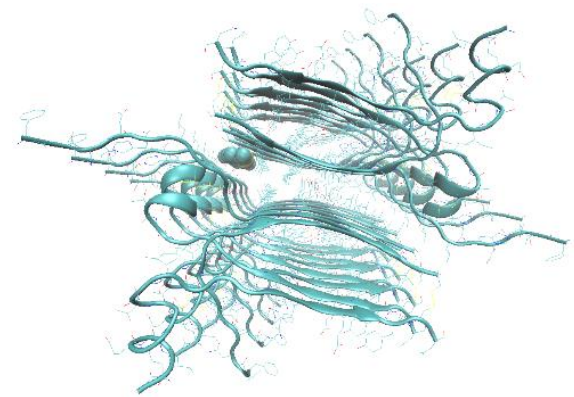

$\mathrm{F}$ 


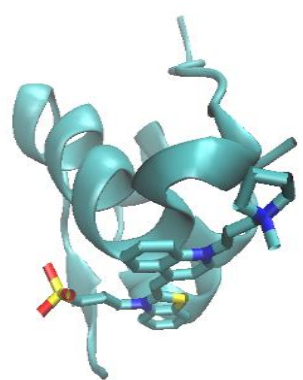

G

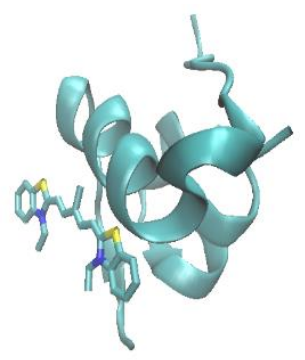

J

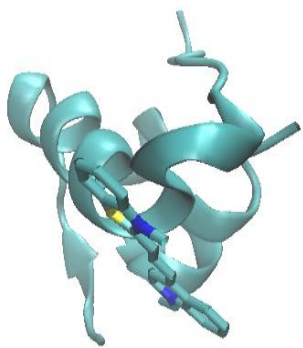

$\mathrm{H}$



$\mathrm{K}$

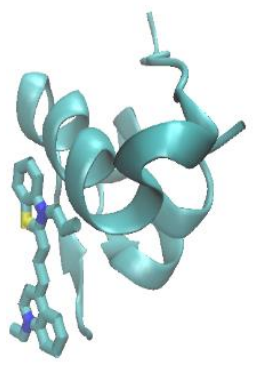

I

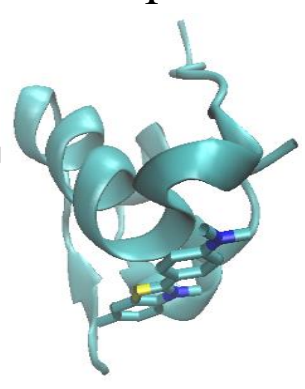

$\mathrm{L}$

\section{Figure 4.}

Schematic representation of the energetically most favourable dye complexes with fibrillar (AE) and native (F-J) insulin, obtained using PatchDock/FireDock servers: AK12-17 (A,G), AK3$1(\mathrm{~B}, \mathrm{H})$, AK3-3 (C,I), AK5-3 (D,J), AK7-6 (E,K), ThT (F,L). AK7-6 is bound to residues L17 and Q4, L6 of the first and second protofilaments (B chain) of fibrillar insulin, respectively, perpendicular to the main fibril axis, while the other dyes associate with L17 ladder of the B chain, located on the dry steric zipper of insulin fibril, parallel to the fibril axis. AK5-3, AK7-6 are attached to the B-chain $\alpha$-helix (residues $10-17$ ) and to B-chain residues $1-4$ ( $\beta$-sheet residues B3-B4) of native insulin. AK3-1, AK12-17, ThT - to the B-chain residues 17-22 (310-helix - residues B20-B22), as well as to B-chain residues 1-4 (AK3-1), F1 (ThT), and Achain $\alpha$-helix (residues 13-17) (AK12-17). AK3-3 is associated with the B-chain residues 10 13 and B-chain residue F1.

unfolded protein conformation compared to the native one [95]. The fact that the hydrophobic (e.g., leucine, valine, alanine) and aromatic (e.g., the B-chain F1 and the A-chain Y14) residues, constitute the insulin binding site for the cyanine dyes, points to the key role of hydrophobic and aromatic intermolecular interactions in the stabilization of the dye-protein complexes. Indeed, fibril formation by the human insulin with mutations to more polar residues retarded the amyloid nucleation, reflecting the high impact of hydrophobic interactions on the protein aggregation [98]. At the same time, the polyphenolic inhibitors (luteolin, transilitin, maritimetin) of A $\beta$ aggregation showed the $\pi-\pi$ stacking interactions with the peptide [78]. Interestingly, the bovine insulin is significantly more prone to fibrillization than the human and porcine insulins due to the A8 residue (A-chain) on the protein surface, enhancing the hydrophobic intermolecular interactions [54]. From this point of view, the ability of the examined dyes to associate with A8 residue (resulting from the fact that these compounds (except monomethines) are characterized by high $\log P$ values (Table S1) similar to the cyanine tau aggregation inhibitor compound 11 [35]) could lead to the increased lag time of insulin fibrillization (Table 1). However, despite the inhibition potency 
of many anti-amyloid therapeutic agents is connected with their tendency to self-associate due to strong stacking interactions with aromatic amino acids, the dye ability to prevent insulin from aggregation showed inverse correlation with $L$, suggesting that either the primary inhibition mechanism is the stabilization of the $\alpha$-helical structure (which manifests itself in the retardation of the protein nucleation and is supported by the docking studies), or that the dye-protein stacking interactions (blocking the lateral extension of $\beta$-sheets) are weaker than those within the dye assemblies, leading to less pronounced effect on $F_{\max }$ and $k$ with the increase of $L[99,100]$. Finally, trimethines occupy both A- and B-chain $\alpha$-helices, which may be responsible for their 24 times higher inhibitory potential than that of the pentamethines (Table $1, F_{\max } / F_{0}$ ). Indeed, when the B-chain $\mathrm{C}$-terminus was tethered with the A-chain $\mathrm{N}$-terminus, the formation of nontoxic amorphous aggregates of the human insulin was observed [101]. It is noteworthy that electrostatic interactions can also play essential role in the formation of critical nucleus, as was demonstrated, in particular, for the human insulin mutants with altered charge, for which the increase in the lag time of amyloid formation was detected [96]. Therefore, the cationic cyanine dyes may inhibit insulin nucleation by interaction with negatively charged amino acids, as well.

Finally, to verify the idea that the inhibitory effect of cyanines on the insulin fibrillization may arise from the stabilization of the native protein structure, we performed a series of molecular dynamics simulations for the five energetically most stable dye-protein complexes. The backbone RMSD and radius of gyration steadily increased as a function of time indicating that the protein structure is significantly denatured during about $10 \mathrm{~ns}$ (Figures S5-S10,A). The helicity of free insulin averaged over all trajectory was $\sim 32 \%$. Similarly, three $\alpha$-helices of the human insulin (whose positions are similar to those of bovine insulin) retain about $50 \%$ of their structure at 60 ${ }^{\circ} \mathrm{C}$, as revealed by CD measurements [102]. It appeared that the dyes under study are capable of stabilizing the insulin native structure (Figure 5A). As illustrated in Figure 5B, the average helicity was higher in the presence of cyanines, with the magnitude of this effect increasing in the row AK12-17 < AK3-1 < AK7-6 < AK5-3 < AK3-3. In general, this row correlates with the inhibition potency of the examined compounds, except AK7-6. The observed stabilization of insulin structure under the influence of cyanines may result from their ability to interact with the B-chain $\alpha$-helix as revealed by the molecular docking. Likewise, SASA per residue decreased in the B-chain (except AK7-6) and A-chain (except AK12-17) helical regions in the presence of cyanines, that is consistent with the involvement of hydrophobic interactions in the formation of the dye-protein complex (Figures S5-S10,B) [103]. Similarly, small stress molecules, the inhibitors of insulin amyloid formation, improved thermostability of the protein by stabilizing the native conformation [97]. Interestingly, AK3-3, possessing the highest inhibition potency, induced the most significant drop in RMSF in the helical regions, compared to other dyes (Figures S5- 
S10,C). Thus, the reduced amino acid flexibility supports the suggestion that cyanine compounds improve thermal stability of insulin similarly to e.g., b-cyclodextrin [104].

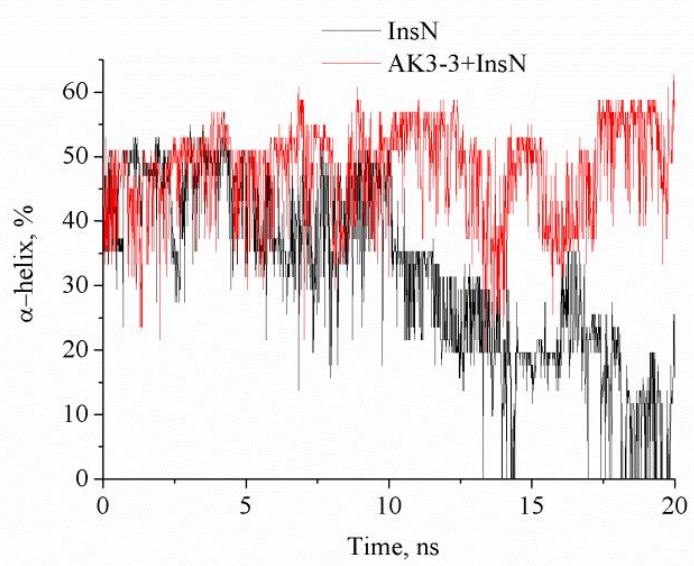

A

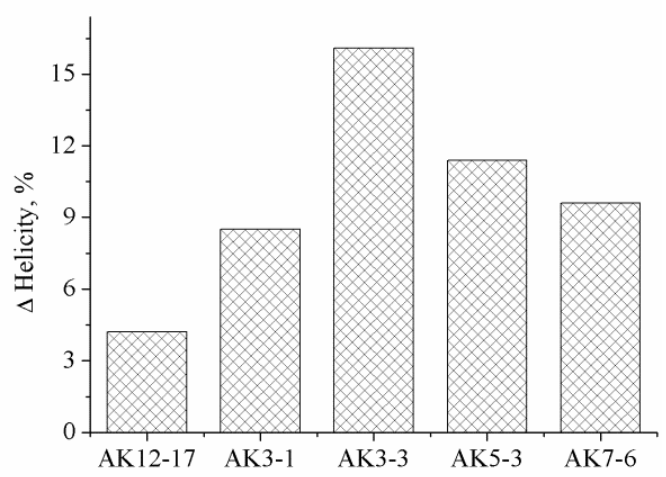

B



$\mathrm{C}$

Figure 5.

$\alpha$-helical content of free insulin monomer (InsN) and bound to AK3-3 plotted vs simulation time (A). Relative changes in the insulin helicity averaged over MD trajectory (20 ns) in the presence of cyanine dyes (B). Schematic illustration of the possible inhibition mechanisms of the insulin aggregation by the cyanine dyes (C). Insulin molecules are colored according to the secondary structure: helices (magenta and pink), beta-sheet (yellow), turns (cyan) and coil (white).

The decreased backbone $R M S D$ and radius of gyration (Figures S5-S10,D) provide evidence for lower denaturation extent and higher degree of structural compactness of insulin in the presence of cyanine dyes. However, the high RMSD values also suggest that the possibility of the stabilization of the partially unfolded insulin conformation by the investigated compounds cannot be excluded. The latter can be explained by more favorable binding to the conformations with the solvent-exposed hydrophobic residues, as was shown, e.g., for the organic fluorogen BSPOTPE that inhibited nucleation and elongation of insulin amyloid fibrils at low dye-protein ratio [95]. 
Based on the above results, the possible inhibition mechanisms of the insulin aggregation by the cyanine dyes can be outlined as follows (Figure 5C): i) stabilization of the native structure by hydrophobic, aromatic and electrostatic interactions, followed by the retardation of the protein nucleation (all dyes); ii) blocking the lateral extension of $\beta$-sheets via the dye-protein stacking interactions (AK3-3, AK3-5, AK5-3, AK5-9).

\section{Conclusions}

In conclusion, ThT fluorescence studies revealed that novel cyanine dyes can effectively inhibit insulin amyloid fibril formation under physiological conditions in vitro at low dye-protein ratio. The compounds possessing the polymethine bridge length of three carbons, long aliphatic substituents (especially those containing OH-groups) on the nitrogen atom of benzazole chromophore were found to display the highest ability to interfere with the protein aggregation. The quantum-chemical calculations, molecular docking and molecular dynamics simulations showed that the cyanines suppress the insulin amyloid nucleation presumably by stabilizing the $\alpha$ helices of the native state, preventing the toxic oligomers formation, unlike many polyphenols (viz., myricetin, baicalein, tannic acid, orcein), which do not interfere with the early nucleation events $[11,105]$. Among the examined dyes, the trimethines AK3-3 and AK3-5 appeared to be the most promising compounds for application in pharmacokinetic studies. Specifically, the effect of nanomolar concentrations of these dyes on insulin amyloid formation can be measured, as well, to enable the design of the anti-amyloid pharmaceutical formulations with the reduced toxicity [33]. Furthermore, the above cyanine compounds are expected to easily cross the blood-brain barrier due to the high lipophilicity and low molecular weight $[33,75,76]$, to have low cytotoxicity due to low affinity for DNA [43], and low ability to exert nonspecific inhibitory effects due to reduced degree of self-association.

\section{Acknowledgements}

This work was partly supported by the grants No 0116U000937 and No 0117 U004966 for Young Scientists from the Ministry of Education Science and of Ukraine (K.V, V.T.). We are grateful to Dr. S. Petrushenko for performing TEM measurements.

\section{Supplementary data}

Supplementary data associated with this article can be found in the online version at:

\section{References}

[1] Cohen FE (1999) Protein misfolding and prion diseases. J Mol Biol 293:313-320. 
[2] Uversky VN, Fink AL (2004) Conformational constraints for amyloid fibrillation: the importance of being unfolded. Biochim Biophys Acta 1698:131-153.

[3] Merlini G, Bellotti V (2003) Molecular mechanisms of amyloidosis. N Engl J Med 349:583-596.

[4] Kayed P, Head E, Thompson JL, McIntire TM, Milton SC, Cotman CW, Glabel CG (2003) Common structure of soluble amyloid oligomers implies common mechanism of pathogenesis. Science 300:486-489.

[5] Kayed R, Lasagna-Reeves CA (2013) Molecular mechanisms of amyloid oligomers toxicity. J Alzheimers Dis 33 Suppl 1:S67-78.

[6] Cohen FE, Kelly JW (2003) Therapeutic approaches to protein-misfolding diseases. Nature 426:905-909.

[7] Miroy GJ, Lai Z, Lashuel HA, Peterson SA, Strang C, Kelly JW (1996) Inhibiting transthyretin amyloid fibril formation via protein stabilization. PNAS 93:15051-15056.

[8] Nasica-Labouze J, Nguyen PH, Sterpone F, Berthoumieu O, Buchete NV, Coté S, De Simone A, Doig AJ, Faller P, Garcia A, Laio A, Li MS, Melchionna S, Mousseau N, Mu Y, Paravastu A, Pasquali S, Rosenman DJ, Strodel B, Tarus B, Viles JH, Zhang T, Wang C, Derreumaux P (2015) Amyloid $\beta$ protein and Alzheimer's disease: When computer simulations complement experimental studies. Chem Rev 115:3518-3563.

[9] Ma JW, Zhao L, Zhao DS, Liu Q, Liu C, Wu WH, Chen YX, Zhao YF, Li YM (2012) A covalently reactive group-modified peptide that specifically reacts with lysine16 in amyloid $\beta$. Chem Commun 48:10565-10567.

[10] Rajasekhar K, Chakrabarti M, Govindaraju T (2015) Function and toxicity of amyloid beta and recent therapeutic interventions targeting amyloid beta in Alzheimer's disease. Chem Commun 51:13434-13450.

[11] Dutta M, Kumar MVS (2015) 39 Inhibition of A $\beta$ aggregation in Alzheimer's disease using the poly-ion short single stranded DNA: in silico study. J Biomol Struct and Dynamics 33: Issue sup 1.

[12] Andujar SA, Lugli F, Höfinger S, Enriz RD, Zerbetto F (2012) Amyloid- $\beta$ fibril disruption by C60-molecular guidance for rational drug design. Phys Chem Chem Phys 14:85998607.

[13] Wang C, Yang A, Li X, Li D, Zhang M, Du H, Li C, Guo Y, Mao X, Dong M, Besenbacher F, Yang Y, Wang C2 (2012) Observation of molecular inhibition and binding structures of amyloid peptides. Nanoscale 4:1895-1909. 
[14] Leri M, Nosi D, Natalello A, Porcari R, Ramazzotti M, Chiti F, Bellotti V, Doglia SM, Stefani M, Bucciantini M (2009) The polyphenol Oleuropein aglycone hinders the growth of toxic transthyretin amyloid assemblies. J Nutr Biochem 30:153-166.

[15] Tanaka M, Komi Y (2015) Layers of structure and function in protein aggregation. Nature Chemical Biology 11:373-377.

[16] Ngoungoure VL, Schluesener J, Moundipa PF, Schluesener H (2014) Natural polyphenols binding to amyloid: A broad class of compounds to treat different human amyloid diseases. Mol Nutr Food Res 59:8-20.

[17] Turnell WG, Finch JT (1992) Binding of the dye congo red to the amyloid protein pig insulin reveals a novel homology amongst amyloid-forming peptide sequences. J Mol Biol 227:1205-1223.

[18] Basu A, Kumar SG (2017) Binding and inhibitory effect of the dyes Amaranth and Tartrazine on amyloid fibrillation in lysozyme. J Phys Chem B 121:1222-1239.

[19] Parthsarathy V, McClean PL, Hölscher C, Taylor M, Tinker C, Jones G, Kolosov O, Salvati E, Gregori M, Masserini M, Allsop D (2013) A novel retro-inverso peptide inhibitor reduces amyloid deposition, oxidation and inflammation and stimulates neurogenesis in the APPswe/PS1 1 E9 mouse model of Alzheimer's disease. PLoS One 8:e54769.

[20] Mishra R, Bulic sB, Sellin D, Jha S, Waldmann H, Winter R (2008) Small-molecule inhibitors of islet amyloid polypeptide fibril formation. Angew Chem Int Ed Engl 47:46794782.

[21] Yang F, Lim GP, Begum AN, Ubeda OJ, Simmons MR, Ambegaokar SS, Chen PP, Kayed R, Glabe CG, Frautschy SA, Cole GM (2004) Curcumin inhibits formation of amyloid beta oligomers and fibrils, binds plaques, and reduces amyloid in vivo. J Biol Chem 280:589258901.

[22] Sun AY, Wang Q, Simonyi A, Sun GY (2010) Resveratrol as a therapeutic agent for neurodegenerative diseases. Mol Neurobiol 41:375-383.

[23] Stefani M, Rigacci S (2014) Beneficial properties of natural phenols: highlight on protection against pathological conditions associated with amyloid aggregation. Biofactors 40:482-493.

[24] Morshedi D, Rezaei-Ghaleh N, Ebrahim-Habibi A, Ahmadian S, Nemat-Gorgani M (2007) Inhibition of amyloid fibrillation of lysozyme by indole derivatives--possible mechanism of action. FEBS J 274:6415-6425.

[25] Mao SS, DiMuzio J, McHale C, Burlein C, Olsen D, Carroll SS (2008) A time-resolved, internally quenched fluorescence assay to characterize inhibition of hepatitis $\mathrm{C}$ virus 
nonstructural protein 3-4A protease at low enzyme concentrations. Anal Biochem 373:18.

[26] Luo S, Zhang E, Su Y, Cheng T, Shi C (2011) A review of NIR dyes in cancer targeting and imaging. Biomaterials 2:7127-7138.

[27] Wu JB, Shi C, Chu GC, Xu Q, Zhang Y, Li Q, Yu JS, Zhau HE, Chung LW (2015) Nearinfrared fluorescence heptamethine carbocyanine dyes mediate imaging and targeted drug delivery for human brain tumor. Biomaterials 67:1-10.

[28] Kurutos A, Ryzhova O, Trusova V, Gorbenko G, Gadjev N, Deligeorgiev T (2016) Symmetric meso-chloro-substituted pentamethine cyanine dyes containing benzothiazolyl/benzoselenazolyl chromophores novel synthetic approach and studies on photophysical properties upon interaction with bio-objects. J Fluoresc 26:177-187.

[29] Kurutos A, Ryzhova O, Trusova V, Gorbenko G, Tarabara U, Gadjev N, Deligeorgiev T (2016) Novel asymmetric monomethine cyanine dyes derived from sulfobetaine benzothiazolium moiety as potential fluorescent dyes for non-covalent labeling of DNA. Dyes and Pigments 130:122-128.

[30] Gadjev NI, Deligeorgiev TG, Kim SH (1999) Preparation of monomethine cyanine dyes as noncovalent labels for nucleic acids. Dyes and Pigments 40:181-186.

[31] Patonay G, Kim JS, Kodagahally R, Strekowski L (2005) Appl Spectrosc 59:682-690.

[32] Necula M, Chirita CN, Kuret J (2005) Cyanine dye N744 inhibits tau fibrillization by blocking filament extension: implications for the treatment of tauopathic neurodegenerative diseases. Biochemistry 44:10227-10237.

[33] Chang E, Congdon EE, Honson NS, Duff KE, Kuret J (2009) Structure-activity relationship of cyanine tau aggregation inhibitors. J Med Chem 52:3539-3547.

[34] Shikama Y, Kitazawa J, Yagihashi N, Uehara O, Murata Y, Yajima N, Wada R, Yagihashi S (2010) Localized amyloidosis at the site of repeated insulin injection in a diabetic patient. Intern Med 49:397-401.

[35] Ivanova MI, Sievers SA, Sawaya MR, Wall JS, Eisenberg D (2009) Molecular basis for insulin fibril assembly. Proc Natl Acad Sci U S A 106:18990-19995.

[36] Brange J, Andersen L, Laursen ED, Meyn G, Rasmussen E (1997) Toward understanding insulin fibrillation. J Pharm Sci 86:517-25.

[37] Gupta Y, Singla G, Singla R (2015) Insulin-derived amyloidosis. Indian J Endocrinol Metab 19:174-177.

[38] Kurutos A, Crnolatac I, Orehovec I, Gadjev N, Piantanida I, Deligeorgiev T (2016) Novel synthetic approach to asymmetric monocationic trimethine cyanine dyes derived from $\mathrm{N}$ - 
ethyl quinolinum moiety. Combined fluorescent and ICD probes for AT-DNA labeling. J Luminescence 174:70-76.

[39] Kurutos A, Ryzhova O, Tarabara U, Trusova V, Gorbenko G, Gadjev N, Deligeorgiev T (2016) Novel synthetic approach to near-infrared heptamethine cyanine dyes and spectroscopic characterization in presence of biological molecules. J Photochem Photobiol A: Chem 328:87-96.

[40] Muzaffar M, Ahmad A (2011) The mechanism of enhanced insulin amyloid fibril formation by $\mathrm{NaCl}$ is better explained by a conformational change model. PLoS One. 6:e27906.

[41] Iannuzzi C, Borriello M, Portaccio M, Irace G, Sirangelo I (2017) Insights into insulin fibril assembly at physiological and acidic $\mathrm{pH}$ and related amyloid intrinsic fluorescence. Int J Mol Sci 18: E2551.

[42] Adachi E, Nakajima H, Mizuguchi C, Dhanasekaran P, Kawashima H, Nagao K, Akaji K, Lund-Katz S, Phillips MC, Saito H (2013) Dual role of an N-terminal amyloidogenic mutation in apolipoprotein A-I. J Biol Chem 288:2848-2856.

[43] Zhou LC, Zhao GJ, Liu JF, Han KL, Wu YK, Peng XJ, Sunc M-T (2007) The charge transfer mechanism and spectral properties of a near-infrared heptamethine cyanine dye in alcoholic and aprotic solvents. J Photochem Photobiol A: Chem 187:305-310.

[44] Binkley S, Pople JA, Hehre WJ (1980) Self-consistent molecular orbital methods. 21. Small split-valence basis sets for first-row elements. J Am Chem Soc 102:939-947.

[45] Scheiner S (2000) Theoretical studies of excited state proton transfer in small model systems. J Phys Chem A 104:5898-5909.

[46] Schmidt MW, Baldridge KK, Boatz JA, ElberT ST, Gordon MS, Jensen JH, Koseki S, Matsunaga N, Nguyen KA, Su S, Windus TL, Dupu is M, Montgomery JA (1993) General atomic and molecular electronic structure system. J Comput Chem 14:1347-1363.

[47] Ertl P, Rohde B, Selzer P (2000) Fast calculation of molecular polar surface area as a sum of fragment based contributions and its application to the prediction of drug transport properties. J Med Chem 43:3714-3717.

[48] Tetko IV, Tanchuk VY (2002) Application of associative neural networks for prediction of lipophilicity in ALOGPS 2.1 program. J Chem Inf Comput Sci 42:1136-1145.

[49] Brange J, Andersen L, Laursen ED, Meyn G, Rasmussen E. (1997) Toward understanding insulin fibrillation. J Pharm Sci 86:517-525.

[50] Dodson G, Steiner D (1998) The role of assembly in insulin's biosynthesis. Curr Opin Struck Biol 8:189-194. 
[51] Pisoni DS, Todeschini L, Borges AC, Petzhold CL, Rodembusch FS, Campo LF (2014) Symmetrical and asymmetrical cyanine dyes. Synthesis, spectral properties, and BSA association study. J Org Chem 79:5511-5520.

[52] Vus K, Tarabara U, Kurutos A, Ryzhova O, Gorbenko G, Trusova V, Gadjev N, Deligeorgiev T (2017) Aggregation behavior of novel heptamethine cyanine dyes upon their binding to native and fibrillar lysozyme. Mol Biosyst 13:970-980.

[53] González MA (2011) Force fields and molecular dynamics simulations. Collection SFN 12:169-200.

[54] Vanquelef E, Simon S, Marquant G, Garcia E, Klimerak G, Delepine JC, Cieplak P, Dupradeau FY (2011) R.E.D. Server: a web service for deriving RESP and ESP charges and building force field libraries for new molecules and molecular fragments. Nucleic Acids Res 39:W511-517.

[55] Mahalka AK, Maury CPJ, Kinnunen PKJ (2011) 1-Palmitoyl-2-(9'-oxononanoyl)-snglycero-3-phosphocholine, an oxidized phospholipid, accelerates finnish type familial gelsolin amyloidosis in vitro. Biochemistry 50:4877-4889.

[56] Kotormán M, Kelemen Z, Kasi PB, Nemcsók J (2018) Inhibition of the formation of amyloid-like fibrils using herbal extracts. Acta Biol Hung 69:125-134.

[57] Nielsen L, Khurana R, Coats A, Frokjaer S, Brange J, Vyas S, Uversky VN, Fink AL (2001) Effect of environmental factors on the kinetics of insulin fibril formation: elucidation of the molecular mechanism. Biochemistry 40:6036-6046.

[58] Fraser PE, Nguyen JT, McLachlan DR, Abraham CR, Kirschner DA (1993) Alpha 1antichymotrypsin binding to Alzheimer A beta peptides is sequence specific and induces fibril disaggregation in vitro. J Neurochem 61:298-305.

[59] Jansen R, Dzwolak W, Winter R (2005) Amyloidogenic self-assembly of insulin aggregates probed by high resolution atomic force microscopy. Biophys J 88:1344-1353.

[60] Dubey K, Anand BG, Shekhawat DS, Kar K (2017) Eugenol prevents amyloid formation of proteins and inhibits amyloid-induced hemolysis. Sci Rep 7:40744.

[61] Uversky VN (2010) Mysterious oligomerization of the amyloidogenic proteins. FEBS J 277:2940-2953.

[62] Krebs MR, Bromley EH, Rogers SS, Donald AM (2005) The mechanism of amyloid spherulite formation by bovine insulin. Biophys J 88:2013-2021.

[63] Lee HH, Choi TS, Lee SJ, Lee JW, Park J, Ko YH, Kim WJ, Kim K, Kim HI (2014) Supramolecular inhibition of amyloid fibrillation by cucurbit[7]uril. Angew Chem Int Ed Engl 53:7461-7465. 
[64] Kisilevsky R, Lemieux LJ, Fraser PE, Kong X, Hultin PG, Szarek WA (1995) Arresting amyloidosis in vivo using small-molecule anionic sulphonates or sulphates: implications for Alzheimer's disease. Nat Med 1:143-148.

[65] Groenning M (2010) Binding mode of thioflavin $\mathrm{T}$ and other molecular probes in the context of amyloid fibrils-current status. J Chem Biol 3:1-18.

[66] Shinde MN, Barooah N, Bhasikuttan AC, Mohanty J (2016) Inhibition and disintegration of insulin amyloid fibrils: a facile supramolecular strategy with p-sulfonatocalixarenes. Chem Commun 52:2992-2995.

[67] Pithadia A, Brender JR, Fierke CA, Ramamoorthy A (2016) Inhibition of IAPP aggregation and toxicity by natural products and derivatives. J Diabetes Res 2046327.

[68] Volkova KD, Kovalska VB, Inshin D, Slominskii YL, Tolmachev OI, Yarmoluk SM (2011) Novel fluorescent trimethine cyanine dye 7519 for amyloid fibril inhibition assay. Biotech Histochem 86:188-191.

[69] Volkova KD, Kovalska VB, Balanda AO, Losytskyy MY, Golub AG, Vermeij RJ, Subramaniam V, Tolmachev OI, Yarmoluk SM (2008) Specific fluorescent detection of fibrillar alpha-synuclein using mono- and trimethine cyanine dyes. Bioorg Med Chem 16:1452-1459.

[70] Kuznetsova IM, Sulatskaya AI, Uversky VN, Turoverov KK (2012) Analyzing thioflavin $\mathrm{T}$ binding to amyloid fibrils by an equilibrium microdialysis-based technique. PLoS One 7:e30724.

[71] Mishra R, Sjölander D, Hammarström P (2011) Spectroscopic characterization of diverse amyloid fibrils in vitro by the fluorescent dye Nile red. Mol Biosyst 7:1232-1240.

[72] Mauro M, Craparo EF, Podesta A, Bulone D, Carotta R, Martorana V, Tianaa G, BiagioSan PL (2007) Kinetics of different processes in human insulin amyloid formation. J Mol Biol 366:258-274.

[73] Chirita C, Necula M, Kuret J (2004) Ligand-dependent inhibition and reversal of tau filament formation. Biochemistry 43:2879-2887.

[74] Masuda M, Suzuki N, Taniguchi S, Oikawa T, Nonaka T, Iwatsubo T, Hisanaga S, Goedert M, Hasegawa M (2006) Small molecule inhibitors of alpha-synuclein filament assembly. Biochemistry 45:6085-6094.

[75] Hou TJ, Xu XJ (2003) ADME evaluation in drug discovery. 3. Modeling blood-brain barrier partitioning using simple molecular descriptors. J Chem Inf Comput Sci 43:21372152. 
[76] Ert P, Rohde B, Selzer P (2000) Fast calculation of molecular polar surface area as a sum of fragment-based contributions and its application to the prediction of drug transport properties. J Med Chem 43:3714-3717.

[77] Schafer KN, Cisek K, Huseby CJ, Chang E, Kuret J (2013) Structural determinants of Tau aggregation inhibitor potency. J Biol Chem 288:32599-32611.

[78] Mahmoodabadi N, Ajloo D (2016) QSAR, docking, and Molecular dynamic studies on the polyphenolic as inhibitors of $\beta$-amyloid aggregation. Medicinal Chemistry Research 25:2104-2118.

[79] Feng BY, Simeonov A, Jadhav A, Babaoglu K, Inglese J, Shoichet BK, Austin CP (2007) A high-throughput screen for aggregation-based inhibition in a large compound library. $\mathbf{J}$ Med Chem 50:2385-2390.

[80] Hannah KC, Armitage BA (2004) DNA-templated assembly of helical cyanine dye aggregates: a supramolecular chain polymerization. Acc Chem Res 37:845-853.

[81] Wu C, Wang Z, Lei H, Zhang W, Duan Y (2007) Dual binding modes of Congo red to amyloid protofibril surface observed in molecular dynamics simulations. J Am Chem Soc 129:1225-1232.

[82] Neidari N, Saboury AA, Meratan AA, Karami L, Sawyer L, Kaboudin B, Jooyan N, Ghasemi A. Polyphenolic self-association accounts for redirecting a high-yielding amyloid aggregation. J Mol Liq 266:291-298.

[83] Karelson M, Lobanov VS, Katritzky AR (1996) Quantum-chemical descriptors in QSAR/QSPR studies. Chem Rev 96:1027-1044.

[84] Parthasarathy V, Pandey R, Stolte M, Ghosh S, Castet F, Würthner F, Das PK, BlanchardDesce M (2015) Combination of cyanine behaviour and giant hyperpolarisability in novel merocyanine dyes: Beyond the bond length alternation (BLA) paradigm. Chemistry 21:14211-14217.

[85] Puyad AL, Chaitanya GK, Thomas A, Paramasivam M, Bhanuprakash K (2013) DFT studies of squarylium and core-substituted squarylium dye derivatives: understanding the causes of the additional shorter wavelength absorption in the latter. J Physical Organic chemistry 26:37-46.

[86] Krebs MR, Bromley EH, Donald AM (2005) The binding of thioflavin-T to amyloid fibrils: localisation and implications. J Struct Biol 149:30-37.

[87] Steinmann D, Nauser T, Koppenol WH (2010) Selenium and sulfur in exchange reactions: a comparative study. J Org Chem 75:6696-6699. 
[88] Manjare ST, Kim Y, Churchill DG (2014) Selenium- and tellurium-containing fluorescent molecular probes for the detection of biologically important analytes. Acc Chem Res 47:2985-2998.

[89] Yu F, Li P, Li G, Zhao G, Chu T, Han K (2011) A near-IR reversible fluorescent probe modulated by selenium for monitoring peroxynitrite and imaging in living cells. $\mathrm{J}$ Am Chem Soc 133:11030-11033.

[90] Wainwright M (2004) Photodynamic therapy - from dyestuffs to high-tech clinical practice. Coloration Technology 34:95-109.

[91] Sakagashira S, Hiddinga HJ, Tateishi K, Sanke T, Hanabusa T, Nanjo K, Eberhardt NL (2000) S20G mutant amylin exhibits increased in vitro amyloidogenicity and increased intracellular cytotoxicity compared to wild-type amylin. Am J Pathol 157:2101-2109.

[92] Cattaneo M, Lecchi A, Randi AM, McGregor JL, Mannucci PM (1992) Identification of a new congenital defect of platelet function characterized by severe impairment of platelet responses to adenosine diphosphate. Blood 80:2787-2796.

[93] Sawaya MR, Sambashivan S, Nelson R, Ivanova MI, Sievers SA, Apostol MI, Thompson MJ, Balbirnie M, Wiltzius JJ, McFarlane HT, Madsen A, Riekel C, Eisenberg D (2007) Atomic structures of amyloid cross-beta spines reveal varied steric zippers. Nature 447:453-457.

[94] Jiang P, Li W, Shea J-E, Mu Y (2011) Resveratrol inhibits the formation of multiplelayered $\beta$-sheet oligomers of the human islet amyloid polypeptide segment 22-27. Biophys J 100:1550-1558.

[95] Hong Y, Meng L, Chen S, Leung CW, Da LT, Faisal M, Silva DA, Liu J, Lam JW, Huang X, Tang BZ (2012) Monitoring and inhibition of insulin fibrillation by a small organic fluorogen with aggregation-induced emission characteristics. J Am Chem Soc 134:16801689.

[96] Wu C, Lei H, Wang Z, Zhang W, Duan Y (2006) Phenol red interacts with the protofibrillike oligomers of an amyloidogenic hexapeptide NFGAIL through both hydrophobic and aromatic contacts. Biophys J 91:3664-3672.

[97] Arora A, Ha C, Park CB (2004) Inhibition of insulin amyloid formation by small stress molecules. FEBS Lett 564:121-125.

[98] Nielsen L, Frokjaer S, Brange J, Uversky VN, Fink AL (2001) Probing the mechanism of insulin fibril formation with insulin mutants. Biochemistry 40:8397-8409.

[99] Kuret J, Chirita CN, Congdon EE, Kannanayakal T, Li G, Necula M, Yin H, Zhong Q (2005) Pathways of tau fibrillization. Biochim Biophys Acta 1739:167-178. 
[100] Kovalska V, Losytskyy M, Chernii V, Volkova K, Tretyakova I, Cherepanov V, Yarmoluk S, Volkov S (2012) Studies of anti-fibrillogenic activity of phthalocyanines of zirconium containing out-of-plane ligands. Bioorg Med Chem 20:330-334.

[101] Huang K, Maiti NC, Phillips NB, Carey PR, Weiss MA (2006) Structure-specific effects of protein topology on cross-beta assembly: studies of insulin fibrillation. Biochemistry 45: 10278-10293.

[102] Hua QX, Weiss MA (2004) Mechanism of insulin fibrillation: the structure of insulin under amyloidogenic conditions resembles a protein-folding intermediate. J Biol Chem 279:21449-21460.

[103] Moraitakis G, Goodfellow JM (2003) Simulations of human lysozyme: probing the conformations triggering amyloidosis. Biophys J 84:2149-2158.

[104] Muhammad EF, Adan R, Latif MAM, Rahman MBA (2016) Theoretical investigation on insulin dimer- $\beta$-cyclodextrin interactions using docking and molecular dynamics simulation. J Inclusion Phenomena and Macrocyclic Chemistry 84:1-10.

[105] Porat Y, Abramowitz A, Gazit E (2006) Inhibition of amyloid fibril formation by polyphenols: structural similarity and aromatic interactions as a common inhibition mechanism. Chem Biol Drug Des 67:27-37. 



Heptamethines

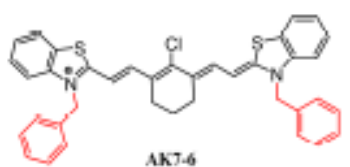

Graphical abstract 


\section{Highlights:}

- The studied cyanine dyes possessed high ability to suppress the insulin fibrillization, as revealed by ThT fluorescence

- Quantum-chemical descriptors of trimethines 3-3, 3-5 and pentamethine 5-3 were similar to those of known amyloid inhibitors

- Molecular docking indicated that most of the compounds bound to the helices of the insulin monomer

- The molecular dynamics simulations showed the stabilization of the insulin $\alpha$-helical structure by the cyanines 